\title{
Natural History of Patients with Acute Proximal Biceps Tendon Rupture
}

\author{
D. P. Axibal ${ }^{1}$, N. C. Yeatts ${ }^{1,2}$, A. J. Rao ${ }^{1}$, K. R. Muña ${ }^{3}$, I. S. Hong ${ }^{1,2}$, P. M. Connor ${ }^{1,2}$, \\ J. E. Fleischli ${ }^{1,2}$, D. P. Piasecki ${ }^{1,2}$, B. M. Saltzman ${ }^{1,2}$, N. Hamid ${ }^{1,2}$ \\ ${ }^{1}$ Sports Medicine Center, OrthoCarolina, Charlotte (NC), U.S.A. \\ ${ }^{2}$ Musculoskeletal Institute, Atrium Health, Charlotte (NC), U.S.A. \\ ${ }^{3}$ OrthoCarolina Research Institute, Charlotte (NC), U.S.A.
}

\section{CORRESPONDING AUTHOR:}

Bryan Saltzman

Sports Medicine Center, OrthoCarolina

Musculoskeletal Institute, Atrium Health

1320 Scott Avenue

Charlotte (NC), U.S.A.

E-mail: Bryan.Saltzman@orthocarolina.com

DOI:

10.32098/mltj.02.2021.03

LEVEL OF EVIDENCE: 2

\begin{abstract}
SUMMARY
Purpose. To determine the natural history of patients presenting with acute proximal biceps rupture (APBR) and concomitant rotator cuff disease.

Methods. Prospective cohort study of patients with an APBR confirmed via magnetic resonance imaging (MRI) presenting to clinic within 8 weeks of injury. Visual Analog Scale (VAS) pain score, Simple Shoulder Test (SST) score, and the American Shoulder and Elbow Surgeons (ASES) score were the main outcome measures assessed at a minimum of two-years.

Results. Twenty-seven patients were included in the final analysis: seven females (26\%) and 20 males (74\%) (mean age: 61 years, range $42-78$ years). Rotator cuff tears were found in 25 patients (93\%). At two-year follow-up (SD 0.28), nine patients (33\%) without improvement or dis-satisfaction with conservative management opted to undergo shoulder surgery (all with rotator cuff tears), at a mean 4.5 months (range 1.2-24 months) after injury. Worker's Compensation and a history of diabetes were significantly associated with having surgery. At the two-year follow-up, the median patient reported outcomes (PROs) were as follows: VAS pain- 0.0 (IQR 0.0-3.0); Disability subscale- 48.3 (IQR 34.2-50.0); ASES total- 89.2 (IQR 70.0-98.3); and SST11.0 (IQR 9.0-12.0). There was no statistically significant difference in PROs between patients who went on to have surgery and those who did not.

Conclusions. Satisfactory PROs and low levels of pain were reported at the two-year follow-up in patients with an APBR, with no difference between those patients who underwent surgical intervention and those who did not.
\end{abstract}

\section{KEY WORDS}

Acute proximal biceps tendon; magnetic resonance imaging; observational study; rotator cuff pathology; shoulder; shoulder injuries.

\section{BACKGROUND}

The unique anatomy and biomechanics of the proximal long head biceps tendon (LHBT) place it at high risk for injury (1-5). Repetitive friction, traction and glenohumeral rotation, with subsequent pressure and shear forces at specific, anatomically constricted locations may account for its susceptibility to rupture $(3,6)$ (figure 1). Still, despite extensive research on the long head of the biceps tendon, controversy persists in regards to its function as well as operative and non-operative management of injury (7-9).
Acute proximal biceps rupture (APBR), presenting in isolation in a less physically demanding patient, can be treated successfully with benign neglect $(10,11)$. However, only recently has literature demonstrated a high prevalence of rotator cuff pathology in patients presenting with a chief complaint of APBR (figure 2). Kowalczuk et al. (12) reported an $85 \%$ prevalence of concomitant rotator cuff tear in the setting of APBR, while the current authors similarly found a $93 \%$ prevalence of rotator cuff pathology with approximately $50 \%$ of patients having a full thickness rotator cuff 


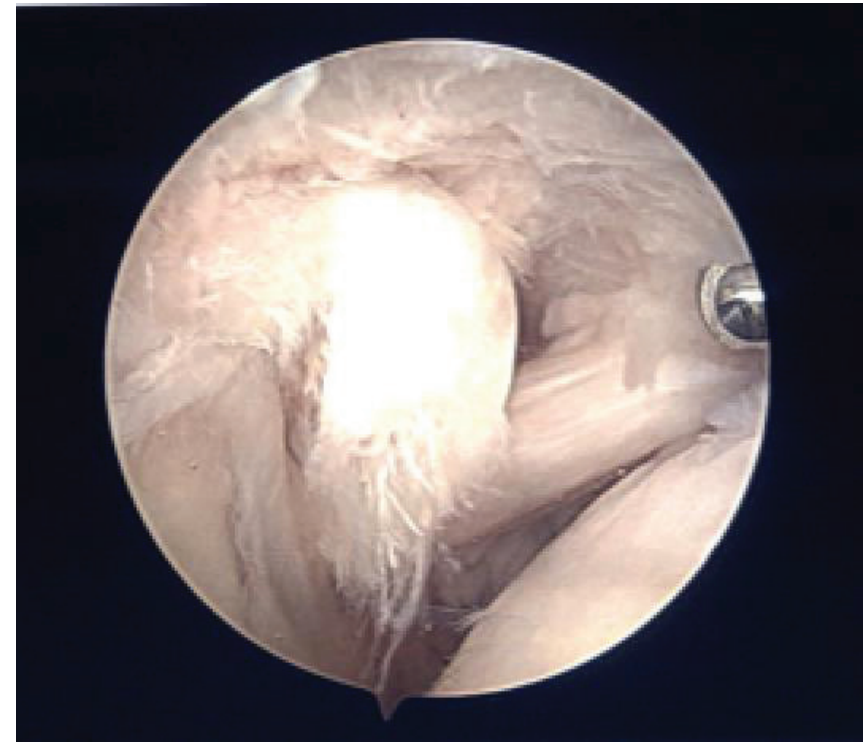

Figure 1. Intraoperative arthroscopic photo of a right shoulder in the beach chair position demonstrating a biceps tendon rupture.

tear (13). As this data suggests that APBR may be a harbinger of concurrent rotator cuff disease, Kowalczuk et al. recommends that clinicians be hypervigilant when presented with an APBR; however, the literature is sparse and the

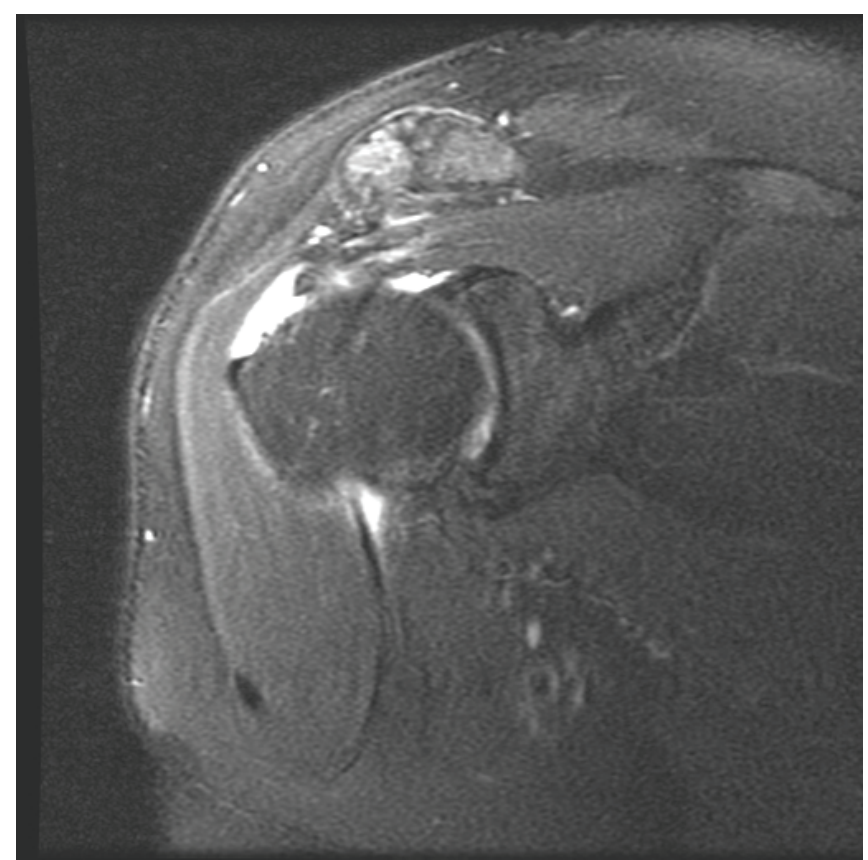

Figure 2. Coronal magnetic resonance image of a right shoulder demonstrating a full-thickness rotator cuff tear. clinical course and outcomes after APBR with associated rotator cuff pathology is poorly understood.

The purpose of this study is to determine the natural history and outcomes of patients presenting with APBR. Our hypothesis was that the majority of patients with APBR would present with concurrent rotator cuff disease, but demonstrate low levels of pain and high patient reported outcome scores regardless of treatment. We also hypothesized that overall low proportion of patients would choose to undergo surgical intervention after failing conservative management strategies.

\section{MATERIALS AND METHODS}

After institutional review board approval, International Classification of Diseases codes (ICD-9) were used to prospectively collect data on 42 consecutive patients from five treating surgeons between September 2015 and February 2017. Patients 18 years or older with a diagnosis of an APBR were included. Acute, injury was defined as presenting to clinic within eight weeks of injury. Patients with a history of ipsilateral shoulder surgery were excluded, as were patients unable to undergo magnetic resonance imaging (MRI) due to contraindications. Patients with incomplete medical records were also excluded. A total of 15 patients were excluded: seven patients were excluded due to previous ipsilateral shoulder surgery, three patients were not seen within the eight-week window deadline, two patients did not have the correct diagnosis, two patients declined participation, and one patient's Worker's Compensation would not allow participation.

Demographics such age, sex, body mass index (BMI), hand dominance, diabetes, tobacco use, Worker's Compensation for the injured shoulder, and mechanism of injury were obtained. Patients underwent routine physical examination and plain radiography as part of their initial assessment. MRI was obtained to confirm the diagnosis of APBR, as well as to allow assessment of the rotator cuff. MRIs were interpreted by a Shoulder/Elbow or Sports Medicine Fellowship-trained orthopedic surgeon. The rotator cuff was recorded as the presence or absence of tearing, and if disrupted, to what degree (full or partial thickness tearing). A subset analysis was performed specifically for the subscapularis tendon.

Primary outcome variables included Visual Analog Scale (VAS) pain score, Simple Shoulder Test (SST) score, and the American Shoulder and Elbow Surgeons (ASES) score. Additional outcome variables included whether or not the patient underwent ipsilateral shoulder surgery for any reason, and risk factors for surgery. Outcomes were noted with a minimum follow-up of two-years. This study meets the ethical standards of the journal (14). 
All data underwent descriptive statistical analysis using SAS version 9.4 (SAS Institute, Cary, NC; http://www.sas.com/ software/sas9). Two groups were defined based on the severity of rotator cuff tear for comparative analysis. A Wilcoxon rank sum test was used for non-parametric continuous variables. A two-sample t test was used for normally distributed data. For categorical variables, a chi-square test (or Fisher's exact test, where appropriate) was used for comparisons between groups. Significance was determined by an alpha level of 0.05 . Study data was collected and managed using REDCap electronic data capture tools hosted at OrthoCarolina Research Institute (15).

\section{RESULTS}

Twenty-seven patients met the inclusion criteria and were included in the final analysis. The median time from injury to clinical evaluation was 21 days (interquartile range, IQR: 9 days, 37 days). There were seven females (26\%) and 20 males $(74 \%)$, with an average age of 61 years (SD: 10; range $42-78$ years). The dominant extremity was affected in 20 shoulders $(74 \%)$, while 11 patients reported antecedent shoulder pain $(41 \%)$. Additional demographic data can be found in table $\mathbf{I}$.

Rotator cuff tears were found in 25 of the 27 patients (93\%). Full thickness tears $(\mathrm{N}=13 ; 52 \%)$ and partial thickness tears $(\mathrm{N}=12 ; 48 \%)$ were seen in almost equal amounts. Seven patients had subscapularis tears in isolation, which were included in the "rotator cuff tear" group (table II).

When stratified by rotator cuff tear, there was no significant difference between the full thickness and partial thickness tear groups in regard to gender, age, dominant extremity, diabetes or other demographic data and injury variables (table III).

By the mean 2.2-year follow-up (SD 0.28, range 1.83-2.75 years), nine patients had undergone ipsilateral shoulder surgery $(33 \%$ ), at a mean time of 4.5 months from injury (range 1.2- 24 months). Seven surgeries were arthroscopic, while two patients underwent reverse shoulder arthroplasty. The seven arthroscopic surgeries included: four rotator cuff repairs, one rotator cuff repair with biceps stump debridement, and two biceps stump debridement, subacromial decompressions, and distal clavicle excisions. The two reverse shoulder arthroplasties were performed for irreparable massive rotator cuff tears (table IV). Worker's Compensation status and a history of diabetes were significantly associated with having surgery, compared to those who did not have surgery (table V).

Patient reported outcomes (PROs) were available on 27 patients at initial presentation to our clinic. The median overall PROs at initial examination were as follows: VAS pain 4 (IQR 1.6-6); disability subscale: 33.3 (IQR 15-43.3); ASES total: 66.7 (IQR 41.7-80.7); and SST: 8 (IQR 3-11).
Table I. Patient demographic data ( $\mathrm{N}=27)$.

\begin{tabular}{ll}
\hline \multicolumn{2}{l}{ Demographic data for patients meeting inclusion criteria } \\
\hline Sex, $\mathbf{n}(\%)$ & $20(74.1 \%)$ \\
\hline Male & $7(25.9 \%)$ \\
\hline Female & $60.6(9.9)$ \\
\hline Age (years), mean (SD) & $28.9(5)$ \\
\hline BMI $\left(\mathrm{kg} / \mathrm{m}^{2}\right)$, mean $(\mathrm{SD})$ & $20(74.1 \%)$ \\
\hline Dominant Side Injury, $\mathrm{n}(\%)$ & $4(14.8 \%)$ \\
\hline Diabetes, $\mathrm{n}(\%)$ & $15(55.6 \%)$ \\
\hline Tobacco Use, $\mathrm{n}(\%)$ & $11(40.7 \%)$ \\
\hline Never & $1(3.7 \%)$ \\
\hline Past & $4(14.8 \%)$ \\
\hline Currently & $11(40.7 \%)$ \\
\hline Contralateral Shoulder Surgery, $\mathrm{n}(\%)$ & $4(14.8 \%)$ \\
\hline Antecedent Shoulder Pain, $\mathrm{n}(\%)$ & \\
\hline Worker's Compensation, $\mathrm{n}(\%)$ & $24(88.9 \%)$ \\
\hline Mechanism of Injury, $\mathrm{n}(\%)$ & $3(11.1 \%)$ \\
\hline Trauma &
\end{tabular}

BMI: Body Mass Index; SD: Standard Deviation.

Table II. MRI details $(\mathrm{N}=27)$.

\begin{tabular}{ll}
\hline MRI Variable & N (\%) \\
\hline Rotator Cuff Tear & \\
\hline No & $2(7.4 \%)$ \\
\hline Yes & $25(92.6 \%)$ \\
\hline Full Thickness Tear & $13(52.0 \%)$ \\
\hline$\quad$ Partial Tear & $12(48.0 \%)$ \\
\hline Subscapularis Tear & \\
\hline No & $20(74.1 \%)$ \\
\hline Partial & $6(22.2 \%)$ \\
\hline Full & $1(3.7 \%)$ \\
\hline
\end{tabular}

When stratified by patients managed by surgical or non-operative treatment, at initial presentation the patients treated non-operatively had significantly better PROs scores in: Disability subscale $(\mathrm{P}$-value $=0.002)$, ASES total $(\mathrm{P}$-value $=$ $0.01)$, and SST $(P$-value $=0.006)($ table VI $)$. Although not statistically significant, VAS pain score at initial exam was lower in patients managed non-operatively.

PROs were available on 22 patients (full thickness: $\mathrm{N}=10$, partial thickness: $\mathrm{N}=10$, no tears: $\mathrm{N}=2$ ) at mean 2.2-year follow up. The median overall PROs scores were as follows: VAS pain: 0.0 (IQR 0.0-3.0); disability subscale: 48.3 (IQR 34.2-50.0); ASES total: 89.2 (IQR 70.0-98.3); and SST: 11.0 (IQR 9.0-12.0). There was no statistically significant difference 
Table III. Demographics and injury variables (stratified by rotator cuff status $(N=27)$ ).

\begin{tabular}{|c|c|c|c|c|}
\hline Demographics and Injury Variables & $\begin{array}{l}\text { Full Thickness } \\
\text { Tear } \\
(\mathrm{N}=13)\end{array}$ & $(\mathrm{N}=12)$ & P-value ${ }^{\dagger}$ & $\begin{array}{l}\text { No Tear } \\
(\mathrm{N}=2)\end{array}$ \\
\hline Sex, n $(\%)$ & & & 0.378 & \\
\hline Male & $8(61.5 \%)$ & $10(83.3 \%)$ & & $2(100 \%)$ \\
\hline Female & $5(38.5 \%)$ & $2(16.7 \%)$ & & $0(0 \%)$ \\
\hline Age (years), mean $(\mathrm{SD})$ & $64(9)$ & $57.6(10.5)$ & 0.115 & $57(8.5)$ \\
\hline BMI $\left(\mathrm{kg} / \mathrm{m}^{2}\right)$, mean $(\mathrm{SD})$ & $27.9(4.5)$ & $30(5.8)$ & 0.328 & $28.5(1.5)$ \\
\hline Dominant Side Injury, n (\%) & $8(61.5 \%)$ & $11(91.7 \%)$ & 0.160 & $1(50 \%)$ \\
\hline Diabetes, $\mathrm{n}(\%)$ & $3(23.1 \%)$ & $1(8.3 \%)$ & 0.593 & $0(0 \%)$ \\
\hline Tobacco Use, n (\%) & & & 0.999 & \\
\hline Never & $7(53.8 \%)$ & $6(50.0 \%)$ & & $2(100 \%)$ \\
\hline Past & $6(46.2 \%)$ & $5(41.7 \%)$ & & $0(0 \%)$ \\
\hline Currently & $0(0 \%)$ & $1(8.3 \%)$ & & $0(0 \%)$ \\
\hline Contralateral Shoulder Surgery, n (\%) & $1(7.7 \%)$ & $2(16.7 \%)$ & 0.593 & $1(50 \%)$ \\
\hline Antecedent Shoulder Pain, n (\%) & $7(53.8 \%)$ & $2(16.7 \%)$ & 0.097 & $2(100 \%)$ \\
\hline Worker’s Compensation, n (\%) & $1(7.7 \%)$ & $3(25.0 \%)$ & 0.322 & $0(0 \%)$ \\
\hline Mechanism of Injury, n (\%) & & & 0.999 & \\
\hline Trauma & $11(84.6 \%)$ & $11(91.7 \%)$ & & $2(100 \%)$ \\
\hline Overuse & $2(15.4 \%)$ & $1(8.3 \%)$ & & $0(0 \%)$ \\
\hline
\end{tabular}

BMI: Body Mass Index; SD: standard deviation. 'Statistical significance tests were performed to look at differences between the Full Thickness Tear group and the Partial Tear group. The No Tear group was not included in the statistical test. Chi-square or fisher's exact tests were used for categorical data and t-tests were used for continuous normally distributed data to determine statistical significance between groups at an alpha level of 0.05 .

Table IV. Surgery data $(\mathrm{N}=9)$.

\begin{tabular}{lll}
\hline $\begin{array}{l}\text { Group } \\
\text { Study ID }\end{array}$ & Procedure & Time from Injury to Surgery \\
\hline Full Thickness Tear $(\mathbf{N}=\mathbf{6})$ & & \\
\hline 01 & RCR, SAD & 1.2 months \\
\hline 05 & RCR, SAD, debridement of biceps tendon stump & 2.8 months \\
\hline 06 & Reverse total shoulder arthroplasty & 24 months \\
\hline 13 & RCR, SAD & 1.4 months \\
\hline 27 & $\begin{array}{l}\text { Reverse total shoulder arthroplasty, latissimus } \\
\text { tendon and teres major tendon transfer }\end{array}$ & 1.4 months \\
\hline 29 & RCR, SAD & 3.3 months \\
\hline Partial Thickness Tear $(\mathbf{N}=\mathbf{3})$ & \begin{tabular}{l} 
\\
\hline 08
\end{tabular} & SAD, DCE, capsular release, debridement of \\
& biceps tendon stump & 1.8 months \\
\hline 10 & SAD, DCE, biceps tenodesis & 1.6 months \\
\hline 11 & RCR, SAD & 3.2 months \\
\hline
\end{tabular}

RCR: rotator cuff repair; SAD: subacromial decompression; DCE: distal clavicle excision 
Table V. Risk factor analysis for surgery $(\mathrm{N}=27)$.

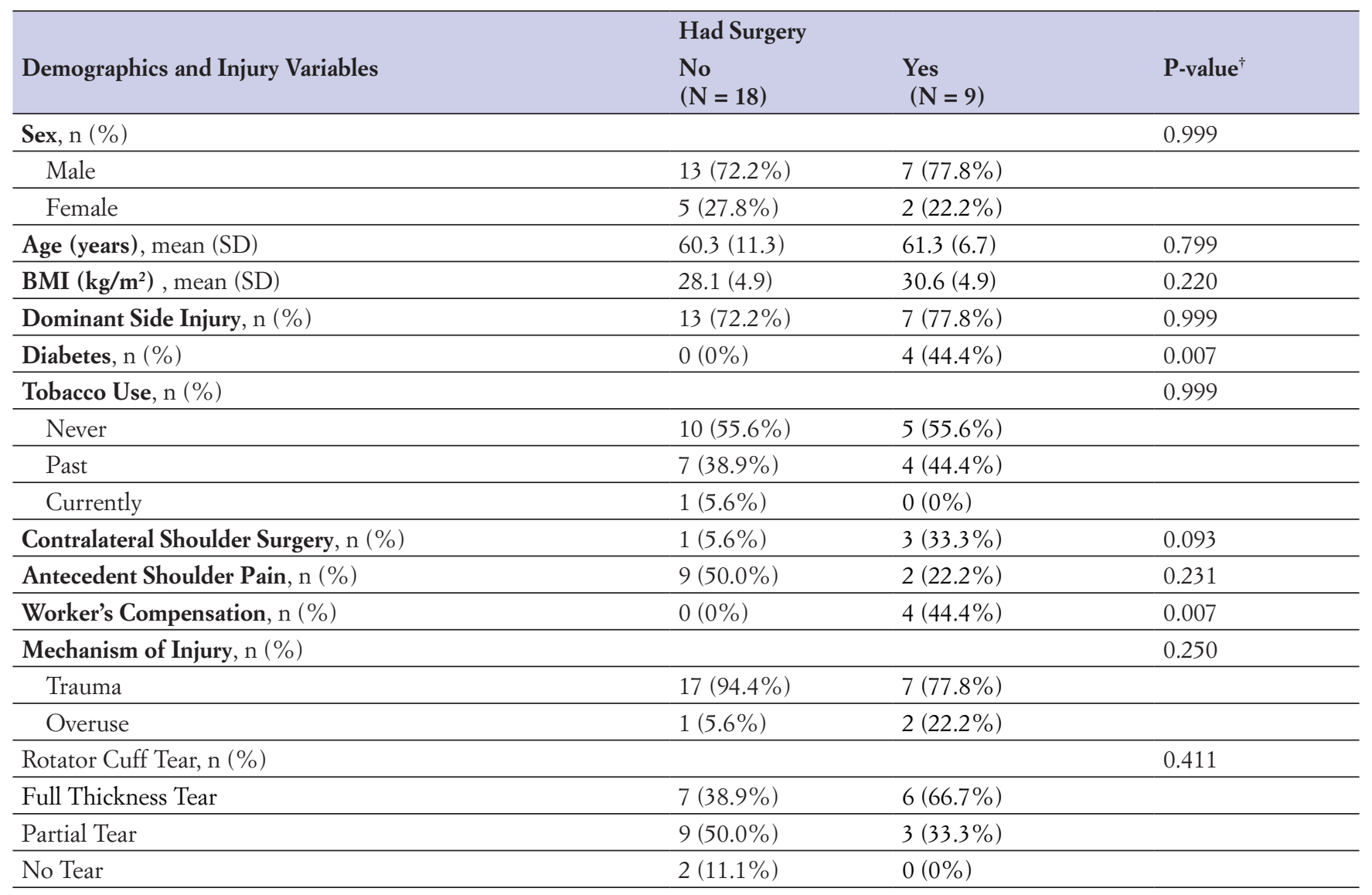

BMI: Body mass Index; SD: standard deviation. ${ }^{\dagger}$ Chi-square or fisher's exact tests were used for categorical data and t-tests were used for continuous normally distributed data to determine statistical significance between groups at an alpha level of 0.05 .

Table VI. Patient reported outcomes at initial exam and at 2 year follow-up (stratified by surgical status).

\begin{tabular}{|c|c|c|c|c|}
\hline & \multicolumn{3}{|c|}{ Surgery } & \multirow[b]{2}{*}{ P-value } \\
\hline & Overall & No & Yes & \\
\hline \multicolumn{5}{|l|}{ At Initial Exam $(\mathrm{N}=27)$} \\
\hline ASES - Function/Disability Subscale, median (IQR) & $33.3(15,43.3)$ & $40(33.3,45)$ & $15(11.7,23.3)$ & 0.002 \\
\hline ASES - Total, median (IQR) & $66.7(41.7,80.7)$ & $78.5(59.8,88.3)$ & $43(33.5,51.7)$ & 0.010 \\
\hline VAS Pain, median (IQR) & $0.0(0.0,3)$ & $0.0(0.0,3)$ & $0.0(0.0,5)$ & 0.817 \\
\hline ASES - Function/Disability Subscale, median (IQR) & $48.3(34.2,50)$ & $48.3(31.7,50)$ & $45(36.7,50)$ & 0.966 \\
\hline ASES - Total, median (IQR) & $89.2(70,98.3)$ & $89.2(70,98.3)$ & $92.5(71.7,100)$ & 0.757 \\
\hline Simple Shoulder Test, median (IQR) & $11(9,12)$ & $11(7,12)$ & $11(9,12)$ & 0.903 \\
\hline
\end{tabular}


Table VII. Patient reported outcomes at $2^{\ddagger}$ year follow-up (overall and stratified by rotator cuff status).

\begin{tabular}{llllll}
\hline \multicolumn{5}{c}{ Stratified by Group } \\
\hline N; Median (IQR) & $\begin{array}{l}\text { Full Thickness Tear } \\
(\mathbf{N}=\mathbf{1 0})\end{array}$ & $\begin{array}{l}\text { Partial Tear } \\
(\mathbf{N}=\mathbf{1 0})\end{array}$ & P-value $^{\dagger}$ & $\begin{array}{l}\text { No Tear } \\
(\mathbf{N}=\mathbf{2})^{*}\end{array}$ & Overall $^{(\mathbf{N}=\mathbf{2 2})}$ \\
\hline ASES (Patient) & & & & & \\
\hline VAS Pain $(\mathbf{0 - 1 0})$ & $10 ; 0.0(0.0,2.5)$ & $10 ; 1.8(0.0,4.0)$ & $\mathbf{0 . 4 2 9}$ & $2 ; 0.0(0.0,0.0)$ & $22 ; 0.0(0.0,3.0)$ \\
\hline $\begin{array}{l}\text { Function/ } \\
\text { Disability Subscale }\end{array}$ & $9 ; 48.3(31.7,50.0)$ & $9 ; 41.7(38.3,48.3)$ & $\mathbf{0 . 9 9 9}$ & $2 ; 49.2(48.3,50.0)$ & $20 ; 48.3(34.2,50.0)$ \\
\hline \multicolumn{1}{|c|}{ ASES Total } & $8 ; 91.7(78.3,99.2)$ & $9 ; 85.0(68.3,98.3)$ & $\mathbf{0 . 5 3 9}$ & $2 ; 99.2(98.3,100)$ & $19 ; 89.2(70.0,98.3)$ \\
\hline Simple Shoulder Test & $10 ; 10.5(7.0,12.0)$ & $9 ; 10.0(9.0,12.0)$ & $\mathbf{0 . 9 9 9}$ & $2 ; 12.0(12.0,12.0)$ & $21 ; 11.0(9.0,12.0)$ \\
\hline
\end{tabular}

IQR: Interquartile Range; ASES: American Shoulder and Elbow Surgeons score; VAS: Visual Analogue Scale. *Time from injury to PRO: mean 2.2 years (SD: 0.28 years); range 1.83-2.75 years. 'Statistical significance tests were performed to look at differences between the Full Thickness Tear group and the Partial Tear group. The No Tear group was not included in the statistical test. Wilcoxon rank-sum tests were used for continuous non-normally distributed data to determine statistical significance between groups at an alpha level of 0.05 . IQR-interquartile range. *Note: the IQR is also the range for this group.

in PROs between the full thickness and partial thickness tear groups (table VII). Furthermore, at mean 2.2-year follow up, there was no statistically significant difference in PROs between patients who went on to have surgery and those who did not.

\section{DISCUSSION}

There is ample literature highlighting patients with rotator cuff tears with concurrent proximal long head biceps tendon pathology (16-19). It has been theorized that adjacent rotator cuff inflammation can lead to secondary biceps tenosynovitis, while subscapularis tears or rotator interval lesions could result in LHBT instability and subsequent tearing (20-22). However, only recently has the literature reported the converse relationship: patients presenting with APBR with concomitant rotator cuff disease $(12,13)$. Furthermore, to our knowledge there is a lack of literature characterizing the natural progression of this specific population. In this prospective cohort study, nine patients $(33 \%)$ had undergone ipsilateral shoulder surgery, at a mean time of 4.5 months from injury. In Kuhn et al.'s study of 319 patients with attempt at conservative treatment for rotator cuff tears, 82 patients eventually had surgery ( $26 \%$ ), with most patients doing so within 12 weeks (23). Our study found that Worker's Compensation status and a history of diabetes were significantly associated with having surgery. Kweon et al. observed younger age and lower BMI were predictive of eventual allocation to surgical treatment in the management of rotator cuff tears (although they did not specifically analyze the variables of Worker's compensation and history of diabetes) (24). There is evidence showing a relationship between thyroid disease non-traumatic rotator cuff tears in females independent of age (25). We did not study the relationship between thyroid pathol- ogies and outcomes in our study population. However, future studies may benefit by investigating if thyroid disorder in a similar cohort of patients to our study is a risk factor for poorer outcomes or predictive of failing conservative treatment and requiring surgery. There currently is no literature on the timeline of conservative treatment of acute proximal biceps ruptures that failed and were allocated to surgical management.

Patients who were treated non-operatively had significantly better PROs in disability subscale, ASES total, and SST at initial clinical presentation. Furthermore, the patients treated non-operatively had lower levels of pain, albeit statistical analysis did not show significance. Indications for surgery included failure to respond or patient dis-satisfaction with conservative treatment entailing physical therapy, non-steroidals, and activity modifications. Of note, all nine patients that underwent surgical intervention had APBR with associated rotator cuff tears. The mean time of 4.5 months from injury to surgical intervention in our study is in accordance with Oliva et al.'s recommendations for treatment of long head of the biceps condition in association with lesions of the rotator cuff. The aforementioned guidelines recommend surgical exploration and possible treatment if symptoms persist for more than 3 months after conservative treatment (26). Lower scores in PROs are equivalent to a greater limitation in shoulder functioning and likely negatively affects patient's motivation and willingness to continue conservative management. As a result, patients may have a lower threshold to seeking surgical treatment.

Our data reveals low levels of pain (VAS median-0.0, IQR 0.0-3.0) and satisfactory PROs (ASES median-89.2, IQR 70.0-98.3; SST median-11.0, IQR 9.0-12.0) at the two-year follow-up, with no difference between patients who went on to have surgery and those who did not. Kim et al. (27), 
Koh et al. (28), Lee et al. (29) found similar outcomes in their studies of rotator cuff repairs with concurrent biceps pathology: SST $9.3 \pm 1.6$ and ASES $88.6 \pm 8.9$, ASES $79.6 \pm$ 15.8, and VAS 2.0 and ASES 82.8, respectively.

We recognize several limitations to our study. It is well known that there is a high incidence of rotator cuff pathology in patients older than 60 years of age. As the average age of our cohort was 61 years, there is potential for confounding bias in our study. Also, each MRI was reviewed by one surgeon, with multiple surgeons $(\mathrm{N}=5)$ included in the study. Intra-observer and inter-observer reliability would increase the validity of our study. However, all reviewers were shoulder/elbow or pports medicine fellowship-trained orthopedic surgeons. Lastly, as the overall sample size is small, it may not be large enough to detect differences between groups. Finally, there was heterogeneity with regard to surgical interventions for the nine patients. Seven patients underwent arthroscopic procedures with two patients receiving reverse shoulder arthroplasty. This may be due to the heterogeneous demographical characteristics of our study population and demonstrates that an individ-

\section{REFERENCES}

1. Eakin CL, Faber KJ, Hawkins RJ, et al. Biceps tendon disorders in athletes. J Am Acad Orthop Surg 1999;7(5):300-10.

2. Frank RM, Cotter EJ, Strauss EJ, et al. Management of Biceps Tendon Pathology: From the Glenoid to the Radial Tuberosity. J Am Acad Orthop Surg 2018;26(4):e77-e89.

3. Nho SJ, Strauss EJ, Lenart BA, et al. Long head of the biceps tendinopathy: diagnosis and management. J Am Acad Orthop Surg 2010;18(11):645-56.

4. Patel KV, Bravman J, Vidal A, et al. Biceps Tenotomy Versus Tenodesis. Clin Sports Med 2016;35(1):93-111.

5. Hsu AR, Ghodadra NS, Provencher MT, et al. Biceps tenotomy versus tenodesis: a review of clinical outcomes and biomechanical results. J Shoulder Elbow Surg 2011;20(2):326-32.

6. Refior HJ, Sowa D. Long tendon of the biceps brachii: sites of predilection for degenerative lesions. J Shoulder Elbow Surg 1995;4(6):436-40.

7. Hassan S, Patel V. Biceps tenodesis versus biceps tenotomy for biceps tendinitis without rotator cuff tears. J Clin Orthop Trauma 2019;10(2):248-56.

8. Gombera MM, Kahlenberg CA, Nair R, et al. All-arthroscopic suprapectoral versus open subpectoral tenodesis of the long head of the biceps brachii. Am J Sports Med 2015;43(5):1077-83.

9. Gurnani N, van Deurzen DF, Janmaat VT, et al. Tenotomy or tenodesis for pathology of the long head of the biceps brachii: a systematic review and meta-analysis. Knee Surg Sports Traumatol Arthrosc 2016;24(12):3765-71.

10. Schickendantz M, King D. Nonoperative Management (Including Ultrasound-Guided Injections) of Proximal Biceps Disorders. Clin Sports Med 2016;35(1):57-73. ualized patient-centered care approach to this population yielded comparable outcomes at the two-year follow-up in patients with conservative or surgical management.

\section{CONCLUSIONS}

This is the first study, to our knowledge, to elucidate on the natural history and outcomes of acute proximal biceps ruptures. In this prospective, observational cohort, $93 \%$ of patients presented with concomitant rotator cuff tears, with $1 / 3$ of patients eventually having surgery. However, low levels of pain and satisfactory PROs were reported at the two-year follow-up, with no difference between those who eventually had surgery and those who did not. These findings allow clinicians to have prognostic discussions with patients presenting with APBR.

\section{CONFLICT OF INTERESTS}

The authors declare that they have no conflict of interests.
11. Wilk KE, Hooks TR. The Painful Long Head of the Biceps Brachii: Nonoperative Treatment Approaches. Clin Sports Med 2016;35(1):75-92.

12. Kowalczuk M, Kohut K, Sabzevari S, et al. Proximal Long Head Biceps Rupture: A Predictor of Rotator Cuff Pathology. Arthroscopy 2018;34(4):1166-70.

13. Vestermark GL, Van Doren BA, Connor PM, et al. The prevalence of rotator cuff pathology in the setting of acute proximal biceps tendon rupture. J Shoulder Elbow Surg 2018;27(7):1258-62.

14. Padulo J, Oliva F, Frizziero A, Maffulli N. Muscles, Ligaments and Tendons Journal - Basic principles and recommendations in clinical and field Science Research: 2018 Update. Muscles Ligaments Tendons J 2018;8(3):305-7.

15. Harris PA, Taylor R, Thielke R, et al. Research electronic data capture (REDCap)--a metadata-driven methodology and workflow process for providing translational research informatics support. J Biomed Inform 2009;42(2):377-81.

16. Braun S, Horan MP, Elser F, et al. Lesions of the biceps pulley. Am J Sports Med 2011;39(4):790-5.

17. Chen CH, Hsu KY, Chen WJ, et al. Incidence and severity of biceps long head tendon lesion in patients with complete rotator cuff tears. J Trauma 2005;58(6):1189-93.

18. Nho SJ, Frank RM, Reiff SN, et al. Arthroscopic repair of anterosuperior rotator cuff tears combined with open biceps tenodesis. Arthroscopy 2010;26(12):1667-74.

19. Mardani-Kivi M, Keyhani S, Ebrahim-Zadeh MH, et al. Rotator cuff tear with concomitant long head of biceps tendon (LHBT) degeneration: what is the preferred choice? Open subpectoral versus arthroscopic intraarticular tenodesis. J Orthop Traumatol 2019;20(1):26. 
20. Ahrens PM, Boileau P. The long head of biceps and associated tendinopathy. J Bone Joint Surg Br 2007;89(8):1001-9.

21. Hsu SH, Miller SL, Curtis AS. Long head of biceps tendon pathology: management alternatives. Clin Sports Med 2008;27(4):747-62.

22. Godenèche A, Nové-Josserand L, Audebert S, et al. Relationship between subscapularis tears and injuries to the biceps pulley. Knee Surg Sports Traumatol Arthrosc 2017;25(7):2114-20.

23. Kuhn JE, Dunn WR, Sanders R, et al. Effectiveness of physical therapy in treating atraumatic full-thickness rotator cuff tears: a multicenter prospective cohort study. J Shoulder Elbow Surg 2013;22(10):1371-9.

24. Kweon C, Gagnier JJ, Robbins CB, et al. Surgical Versus Nonsurgical Management of Rotator Cuff Tears: Predictors of Treatment Allocation. Am J Sports Med 2015;43(10):2368-72.
25. Oliva F, Osti L, Padulo J, Maffulli N. Epidemiology of the rotator cuff tears: a new incidence related to thyroid disease. Muscles Ligaments Tendons J 2014;4(3):309-14.

26. Oliva F, Piccirilli E, Bossa M, et al.I.S.Mu.L.T - Rotator Cuff Tear Guidelines. Muscles Ligaments Tendons J 2015;5(4):227-63

27. Kim SJ, Lee IS, Kim SH, et al. Arthroscopic repair of concomitant type II SLAP lesions in large to massive rotator cuff tears: comparison with biceps tenotomy. Am J Sports Med 2012;40(12):2786-93.

28. Koh KH, Ahn JH, Kim SM, et al. Treatment of biceps tendon lesions in the setting of rotator cuff tears: prospective cohort study of tenotomy versus tenodesis. Am J Sports Med 2010;38(8):1584-90.

29. Lee HJ, Jeong JY, Kim CK, et al. Surgical treatment of lesions of the long head of the biceps brachii tendon with rotator cuff tear: a prospective randomized clinical trial comparing the clinical results of tenotomy and tenodesis. J Shoulder Elbow Surg 2016;25(7):1107-14. 